General Mathematics Vol. 28, No. 2 (2020), 61-65

DOI: $10.2478 / \mathrm{gm}-2020-0015$

S sciendo

\title{
Ulam stability for Thunsdorff and Cauchy-Schwarz equations ${ }^{1}$
}

\author{
Laura Hodiş
}

\begin{abstract}
We consider the equality case in Thunsdorff inequality and Cauchy-Schwarz inequality. For these two equations we prove Ulam stability.
\end{abstract}

2010 Mathematics Subject Classification: 26D15.

Key words and phrases: Thunsdorff inequality, Cauchy-Schwarz inequality, Ulam stability.

\section{Introduction}

Briefly speaking, an equation is called Ulam stable if for each "approximate solution" $x$, there exists an exact solution $x_{0}$ "near $x$ ". The precise definitions, in various contexts, can be found, e.g., in [3].

We consider Thunsdorff's inequality (see [9], [8], [7]) and Cauchy-Schwarz inequality. The corresponding equality cases provide two equations for which we prove specific forms of Ulam stability.

\section{Ulam stability for Thunsdorff equation}

We start with Thunsdorff inequality:

Theorem 1 Let $f \in C[0,1]$ be convex, $f \geq 0, f(0)=0$. If $0<p<q$, then

$$
\left(\int_{0}^{1} f^{p}\right)^{\frac{1}{p}} \leq(q+1)^{\frac{1}{q}}(p+1)^{-\frac{1}{p}}\left(\int_{0}^{1} f^{q}\right)^{\frac{1}{q}}
$$

\footnotetext{
${ }^{1}$ Received 26 July, 2020

Accepted for publication (in revised form) 20 September, 2020
} 
We consider the particular case $p=1, q=2$. According to Th.1, if $f \in C[0,1]$ is convex, $f \geq 0$ and $f(0)=0$, then

$$
2 \int_{0}^{1} f(x) d x \leq \sqrt{3} \sqrt{\int_{0}^{1} f^{2}(x) d x}
$$

i.e.,

$$
3 \int_{0}^{1} f^{2}(x) d x-4\left(\int_{0}^{1} f(x) d x\right)^{2} \geq 0 .
$$

Obviously, this inequality is stronger than the Cauchy-Schwarz inequality applied to $f$, namely

$$
\int_{0}^{1} f^{2}(x) d x-\left(\int_{0}^{1} f(x) d x\right)^{2} \geq 0 .
$$

We associate to (1) the Thunsdorff equation

$$
3 \int_{0}^{1} f^{2}(x) d x-4\left(\int_{0}^{1} f(x) d x\right)^{2}=0
$$

and to (2) the Cauchy-Schwarz equation

$$
\int_{0}^{1} f^{2}(x) d x-\left(\int_{0}^{1} f(x) d x\right)^{2}=0 .
$$

For each $\lambda \in \mathbb{R}$, the function $f(x):=\lambda x, x \in[0,1]$, is a solution of (3), and $f(x):=\lambda, x \in[0,1]$, is a solution of (4).

The following theorem expresses the Ulam stability of Thunsdorff's equation.

Theorem 2 Let $\varepsilon>0$ and $g \in C[0,1]$ convex, $g \geq 0, g(0)=0$, such that

$$
3 \int_{0}^{1} g^{2}(x) d x-4\left(\int_{0}^{1} g(x) d x\right)^{2} \leq 3 \varepsilon .
$$

Then there exists an exact solution of (3) such that

$$
\int_{0}^{1}(g(x)-f(x))^{2} d x \leq \varepsilon .
$$

Proof. Let $\lambda \in \mathbb{R}$. According to (5) we have

$$
\begin{aligned}
\int_{0}^{1}(g(x)-\lambda x)^{2} d x & =\int_{0}^{1} g^{2}(x) d x-2 \lambda \int_{0}^{1} x g(x) d x+\frac{1}{3} \lambda^{2} \\
& \leq \frac{4}{3}\left(\int_{0}^{1} g(x) d x\right)^{2}+\varepsilon-2 \lambda \int_{0}^{1} x g(x) d x+\frac{1}{3} \lambda^{2} .
\end{aligned}
$$


i.e.,

$$
\int_{0}^{1}(g(x)-\lambda x)^{2} d x \leq \frac{1}{3}\left(\lambda^{2}-6 \lambda \int_{0}^{1} x g(x) d x+4\left(\int_{0}^{1} g(x) d x\right)^{2}\right)+\varepsilon .
$$

Consider the equation

$$
\lambda^{2}-6 \lambda \int_{0}^{1} x g(x) d x+4\left(\int_{0}^{1} g(x) d x\right)^{2}=0 .
$$

Its discriminant is

$$
\begin{aligned}
\Delta & =36\left(\int_{0}^{1} x g(x) d x\right)^{2}-16\left(\int_{0}^{1} g(x) d x\right)^{2} \\
& =4\left(3 \int_{0}^{1} x g(x) d x+2 \int_{0}^{1} g(x) d x\right)\left(3 \int_{0}^{1} x g(x) d x-2 \int_{0}^{1} g(x) d x\right) .
\end{aligned}
$$

Since $g \geq 0$, we have

$$
3 \int_{0}^{1} x g(x) d x+2 \int_{0}^{1} g(x) d x \geq 0 .
$$

Moreover,

$$
3 \int_{0}^{1} x g(x) d x-2 \int_{0}^{1} g(x) d x=\int_{0}^{1}(3 x-2) g(x) d x .
$$

The function $g$ is convex, $g \geq 0, g(0)=0$; it follows that it can be uniformly approximated on $[0,1]$ with linear combinations of functions of the form $\varphi(x):=\max \{0, x-a\}, a \in[0,1)$, all the coefficients of the linear combinations being positive.

Since

$$
\int_{0}^{1}(3 x-2) \max \{0, x-a\} d x=\frac{1}{2} a(1-a)^{2} \geq 0, a \in[0,1),
$$

it follows that

$$
\int_{0}^{1}(3 x-2) g(x) d x \geq 0 .
$$

Now (10) and (11) show that

$$
3 \int_{0}^{1} x g(x) d x-2 \int_{0}^{1} g(x) d x \geq 0 .
$$

From (9) and (12) we infer that $\Delta \geq 0$, and therefore the equation (8) has a real $\operatorname{root} \lambda_{0}$.

According to (7) we have

$$
\int_{0}^{1}\left(g(x)-\lambda_{0} x\right)^{2} d x \leq \varepsilon,
$$

and so (6) is satisfied with $f(x)=\lambda_{0} x, x \in[0,1]$, which is an exact solution of (3). 


\section{Ulam stability for Cauchy-Schwarz equation}

The Cauchy-Schwarz equation (4) has a similar property of Ulam stability.

Theorem 3 Let $\varepsilon>0$ and $g \in C[0,1]$ such that

$$
\int_{0}^{1} g^{2}(x) d x-\left(\int_{0}^{1} g(x) d x\right)^{2} \leq \varepsilon
$$

Then there exists an exact solution $f$ of (4) such that

$$
\int_{0}^{1}(g(x)-f(x))^{2} d x \leq \varepsilon
$$

Proof. Let $\lambda \in \mathbb{R}$. Then

$$
\begin{aligned}
\int_{0}^{1}(g(x)-\lambda)^{2} d x & =\int_{0}^{1} g^{2}(x) d x-2 \lambda \int_{0}^{1} g(x) d x+\lambda^{2} \\
& \leq\left(\int_{0}^{1} g(x) d x\right)^{2}+\varepsilon-2 \lambda \int_{0}^{1} g(x) d x+\lambda^{2} \\
& =\left(\lambda-\int_{0}^{1} g(x) d x\right)^{2}+\varepsilon
\end{aligned}
$$

Taking $\lambda_{0}=\int_{0}^{1} g(x) d x$, we see that $\int_{0}^{1}\left(g(x)-\lambda_{0}\right)^{2} d x \leq \varepsilon$ and so (14) is satisfied with $f(x)=\lambda_{0}, x \in[0,1]$, which is an exact solution of (4).

Remark 1 The Ulam stability for some classical functional equations (Cauchy, Jensen, Quadratic equations) was investigated in [6], [3, Chapter 4]. In this case the best (i.e., smallest) Ulam constant was determined. For the pertinent definitions see e.g., [3, Chapter 4]. The Ulam stability can be investigated for other equations associated with classical inequalities which can be found, e.g., in [1], [2], [4], [5].

\section{References}

[1] H. Alzer, On an integral inequality for concave functions, Acta. Sci. Math., vol. 56, 1992, 79-82.

[2] S. Barza, C. P. Niculescu, Integral equations for concave functions, Publ. Math. Debrecen, vol. 68, 2006, 139-159.

[3] J. Brzdek, D. Popa, I. Raşa, B. Xu, Ulam stability of Operators, Academic Press, Elsevier, 2018.

[4] A. M. Fink, M. Jodeit Jr., Jensen inequalities for functions with monotonicities, Aeq. Mathematicae, vol. 40, 1990, 26-43. 
[5] M. Petschke, Extremalstrahlen konvexer Kegel un komplementäre Ungleichungen, Dissertation Darmstadt, 1989.

[6] D. Popa, I. Raşa, Best constant in Hyers-Ulam stability of some functional equations, Carpathian J. Math., vol. 30, 2014, 383-386.

[7] I. Raşa, T. Vladislav, Inegalităţi şi aplicaţii, Editura Tehnică, Bucureşti, 2000.

[8] L. Stanković, Extentions of Thunsdorff's inequality to the case of convex functions of order $k$, Univ. Beograd, Publ. Elektrotehn. Fak. Mat. Fiz., no. 498-541, 1975, 145-148.

[9] H. Thunsdorff, Konvex Funktionen und Ungleichungen, Univ. of Göttingen, 1932.

\section{Laura Hodiş}

Technical University of Cluj-Napoca

Department of Mathematics

Str. Memorandumului, nr. 28, Cluj-Napoca, Romania

e-mail: mesaros.laura@gmail.com 